\begin{tabular}{|l|l|}
\hline $\begin{array}{l}\text { Postprint } \\
\text { Version }\end{array}$ & 1.0 \\
\hline Journal website & http://dx.doi.org/10.1016/j.ufug.2007.03.003 \\
\hline Pubmed link & $10.1016 /$ j.ufug.2007.03.003 \\
\hline DOI & This is a NIVEL certified Post Print, more info at http://www.nivel.eu \\
\hline
\end{tabular}

\title{
Are health benefits of physical activity in natural environments used in primary care by general practitioners in The Netherlands?
}

\author{
J. MAAS, R.A. VERHEIJ
}

\begin{abstract}
There is a growing body of literature showing that physical activity and nature have a positive effect on people's health and well-being. Additionally literature indicates that there may even be a synergic benefit from being physically active whilst simultaneously being directly exposed to nature. This insight is used in recovery programmes for work related stress and mental health care settings. However, as primary care is usually people's first point of contact with the health care system, the greatest benefits for people's health can probably be obtained in primary health care settings. The aim of the present study is therefore to investigate to what extent general practitioners advise patients on physical activity and whether they refer to the additional health benefits of physical activity in a natural environment.
\end{abstract}

A secondary analysis was performed on a random sample of 2784 video-taped patient consultations of 100 general practitioners in The Netherlands. Many characteristics of these consultations were known on the basis of earlier analyses: diagnosis, age and sex of patient and whether or not the issue of physical activity had been brought up by either patient or doctor. First, we investigated to what extent and with which health problems advice was given concerning physical activity. Second, from these consultations, a stratified sample of 100 consultations was observed in order to investigate whether an advice was given by the general practitioner concerning the additional benefits of nature. In $26 \%$ of all consultations advice on physical activity was given by the general practitioner. Physical activity was mentioned more often in cases of vague complaints than in cases with a clear cut diagnosis. As could have been expected, physical activity was mentioned relatively frequently in cases of musculoskeletal complaints and complaints of the nervous system. The additional benefits of physical activity in natural environments was not mentioned during any of the consultations.

In conclusion, general practitioners regularly give advice on physical activity. However, they fail to mention that physical activity in nature areas might have 
additional health benefits. Given the fact that medical treatment is increasingly evidence based, we think the evidence for the health benefits of physical activity in nature needs to be stronger. Results from such research could eventually find their way into the guidelines of the general practitioners.

\section{INTRODUCTION}

Given the growing public health concern about obesity, diabetes and heart diseases, there is increasing attention for the benefits of physical activity for people's health and well-being (NIH Consensus Development Panel on Physical Activity and Cardiovascular Health, 1996; Oguma et al., 2002). In addition, there is also growing evidence of a positive relation between health and the amount of green space in people's environment (Maas et al., 2006). Combining these two positive relations of both physical activity and a natural environment with health, it seems only logical, that physical exercise in a natural environment should have additional benefits compared with physical exercise in an unnatural environment. Support for this last hypothesis was found by Hartig et al. (1991) and Pretty et al. (2005). The aim of this study is to investigate to what extent advice on physical activity is given in primary care, and to what extent the additional benefits of physical activity in nature areas are used in primary care consultations.

Physical activity and health There is a large body of evidence pointing towards the health benefits of regular physical activity (Oguma et al., 2002). All studies indicate that being physically active is good for people's health and/or well-being (Pate et al., 1995; US Department of Health and Human Services, 1996; NIH Consensus Development Panel on Physical Activity and Cardiovascular Health, 1996; Scully et al., 1998; Ru" tten, 2001). More specifically, the literature shows that physical activity can provide long-term protection against a range of illnesses.

The most important and most frequently cited illnesses are coronary heart disease, hypertension, a number of cancers, type II diabetes, osteoporosis, anxiety and depression and all-cause mortality (Pate et al., 1995; Scully et al., 1998). Physical activity has an important role in health promotion and the prevention of disease (Scully et al., 1998; Booth et al., 2000).

\section{Nature and health}

There is also a growing body of literature on the relationship between the physical environment and people's health. The negative health effects of air pollution, bad housing and noise have been known for many years. On top of this, there seems to be a renewed consciousness about the positive health effects of a natural environment. A natural environment can include for example parks, forests, trees, public gardens, but also agricultural green space. In 2004, the Health Council of the Netherlands concluded on the basis of an international literature review, that there are consistent cues for assuming a positive link between nature and health, though more research was needed. Most evidence comes from experimental psychological studies on the effect of nature on recovery from stress andattention fatigue. These studies suggest that nature has a positive effect on mood, concentration, self-discipline and physiological stress. Even after brief exposure to a natural environment, beneficial effects occur (Kaplan and Kaplan, 1989; Hull, 1992; Health Council of the Netherlands and Nature and the environment Dutch Advisory Council for research on Spatial Planning, 2004). Ulrich, for example, showed in 1984 that patients with a view of trees recovered more quickly from a gall bladder operation than people who viewed a brick wall during their recovery (Ulrich, 1984). Research concerning American prisoners indicated that prisoners who had view over grass and forests less often reported ill, compared with prisoners whose cells faced a brick yard (Moore and Arch, 1982). Moreover, two large scale epidemiological studies show a positive relation between the amount of green space in 
Maas, J. Are health benefits of physical activity in natural environments used in primary care by general practitioners in The Netherlands? Urban Forestry \& Urban Greening: 2007, 6(4), 227-233

people's living environment and self-reported health (de Vries et al., 2003; Maas et al., 2006).

Besides having positive effects on stress and attention restoration, nature might also influence the amount of physical activity. Natural environments are perceived as more attractive than built environments (van den Berg et al., 2003). Therefore, green areas may act as an incentive for residents to undertake healthy physical activities such as walking or cycling or to choose these activities as a mode of transport, and to spend more time on them (Taylor et al., 1998).

Similar suggestions were made by Ellaway et al.

(2005), who showed that people living in a green environment, have a three times higher probability of being physically active, and a $40 \%$ smaller probability of being overweight or obese. Furthermore, research in the Netherlands showed that children with more green in their living environment, fewer high rise buildings and more outdoor sports facilities were more physically active (de Vries et al., 2007).

\section{Physical activity in a natural environment and health}

The previous section shows that both physical activity and nature are positively related to people's health condition. Additionally, there are indications that being physically active in a natural environment has synergic effects on people's health as opposed to being physically active elsewhere. Hartig et al. (1991) found that walking in a natural environment had significant better restorative effects than walking in urban surroundings. People who walked in a natural environment experienced a sense of being away, coherence, and compatibility to a higher degree than did people who went for a walk in a urban environment. The people who walked in a natural environment had higher ratings on overall happiness and lower ratings on anger and aggression scores. A study from Bodin and Hartig (2003) found that regular runners preferred the park to urban environments.

The restorative effects were only slightly but not significantly higher in a park.

Pretty et al. (2005) showed that watching a rural pleasant environment while exercising indoor had the greatest effects in reducing blood pressure and in improving the mood as opposed to watching rural unpleasant and urban environments.

\section{Use of health benefits of nature in health care settings}

Summing up, there is reason to believe that the relation between physical activity and nature on the one hand and health on the other hand, can be used in health care settings. To some degree this is already happening in hospitals and nursing homes (van den Berg, 2005). One example of the way in which nature is used in these health care sectors is through healing gardens. These healing gardens are, among other things, designed to make people feel safe, less stressed and more comfortable.

Furthermore, agricultural farms are used as a basis for promoting human mental and physical health and social well-being. On these farms, animals, plants, the garden, the forest and the landscape are used in recreational or work related activities for different kinds of patients. The number of these farms is increasing rapidly in many countries (Hassink and van Dijk, 2006).

\section{Use of health benefits of physical activity in nature in primary care}

The health benefits of physical activity in natural environments are also used in primary care in some countries. In the United Kingdom (UK), initiatives for promoting physical activity in a natural environment started when an Oxfordshire general practitioner began prescribing outdoor exercise instead of valium for depressive illness in 1995. He started to see impressive results from his prescriptions. This resulted, among other things, in over 50 Green Gyms in the UK to date.

Participants of Green Gyms exercise in the countryside or open spaces. Participants can also take part in conservation activities such as tree planting, hedgelaying, fostering rare plants \& animals, restoring ancient downland. This offers an alternative for people who do not like the idea of joining a sports centre or gym (see Green Gym, 2007). A New Zealand 
Maas, J. Are health benefits of physical activity in natural environments used in primary care by general practitioners in The Netherlands? Urban Forestry \& Urban Greening: 2007, 6(4), 227-233

study (Elley et al., 2003) showed that people who get written physical activity (PA) advice from their general practitioner are more physically active and have a better quality of life.

The above examples suggest that there are possibilities to use physical activity in nature areas for health promotion purposes in primary care settings. Primary care can play an important role in the prevention of obesity, stress related illnesses, diabetes, and heart disease. This is particularly true for countries where primary care doctors are providing continuous care for the whole population and where it is usually people's first point of contact with the health care system.

However, the extent to which primary care patients are given advise on physical activity in natural environments is not known. In this paper we try to fill this gap by addressing the following sequence of questions:

- To what extent do general practitioners offer advice on physical activities?

- Which health problems induce this type of advice?

- To what extent does the likelihood of this type of advice depend on socio-demographic characteristics of the patient?

-To what extent does the likelihood of this type of advice depend on characteristics of the general practitioner?

-To what extent does this type of advice include any reference to nature or green space? As primary care in the Netherlands is mainly a matter of general practices, it was decided to focus on patient consultations in general practice.

Method The data that were used for this study were derived from the Second Dutch National Survey of General Practice (DNSGP-2). Aim of DNSGP-2 was to monitor public health and health inequalities. The dataset includes data from a representative sample of 104 general practices, with 195 general practitioners and about 350,000 patients (Westert et al., 2005). Within the framework of DNSGP-2, 2784 consultations of general practitioners were videotaped with the aim to get more insight into the communication between general practitioners and their patients. Data collection took place in 2001.

Physical activity In an earlier study, all video tapes were observed and scored on a number of aspects on the basis of validated observation protocols (van den Brink-Muinen et al., 2004). One of the aspects on which the video tapes were judged, was whether or not a lifestyle recommendation concerning 'physical activity' was discussed during the consultation. In the remainder of this paper, this will be referred to as the presence of a PA advice.

\section{Nature}

The original observation protocols did not render information about whether or not nature areas or similar terms came up during the consultations. The videotapes needed to be viewed and judged again. There were 564 videotapes that contained PA advice. Of these, a random sample of 100 tapes were viewed again to see whether or not any reference was made to nature, green space, forests, or similar terms. A total of 10 of these tapes were also viewed by a second observer.

Diagnoses For each consultation, symptoms/diagnoses were recorded by the general practitioner using the International Classification of Primary Care (ICPC) (Lamberts and Wood, 1987). This is a classification with 17 chapters on the basis of 17 functions of the body. In each chapter a distinction is made between symptoms and diagnosis codes. Symptom codes are used if a general practitioner is unable to diagnose a patient. A stomach ache that a general practitioner can not diagnose, will be recorded simply as a stomach ache (symptom). In a later consultation he or she might diagnose it as appendicitis (diagnosis).

Patient characteristics The following patient characteristics have been taken into account to examine to what extent the likelihood of PA advice depends on characteristics of the patient: gender, age $(0-15,16-25,26-40,41-55,56-65,>65)$, level of education (no education, elementary school, high school, higher education/university) or type of health insurance (public or private). The type of health insurance has been taken into account, because it can 
Maas, J. Are health benefits of physical activity in natural environments used in primary care by general practitioners in The Netherlands? Urban Forestry \& Urban Greening: 2007, 6(4), 227-233

be regarded as an indicator of socio-economic status in The Netherlands, with public insurance for about $60 \%$ of the population (lower incomes) and private insurance for the rest (higher incomes) (World Health Organization, 1997). These characteristics are taken into account because they are all closely related to people's health condition and to their level of physical activity.

General practitioners characteristics The following general practitioner characteristics have been taken into account to examine to what extent the likelihood of PA advice depends on characteristics of the general practitioner: gender, age (30-39, 40-49, 50-59, 60-69 years), type of practice (single handed, duo or group) and number of working hours (expressed in fulltime equivalents (fte)). Furthermore, we investigated whether the likelihood of PA advice depends on the level of urbanity of the practice location. The level of urbanity is divided into five levels ranging from very highly urban (1) to non-urban (5). The indicator is based on the number of households per square kilometre and is commonly used in the Netherlands (den Dulk et al., 1999).

Analyses The analyses concerning patient and general practitioner characteristics were limited to those complaints that are theoretically related to people's level of physical activity. In this manner we were able to account for differences in prevalence between different patient categories and differences in the case mix of general practitioners. The following complaints were selected: fatigue, high blood pressure, overweight, diabetes, complaints concerning the musculoskeletal apparatus and mental complaints. After making this selection 829 consultations remained.

The data were analysed using the SPSS software package. Tests for significance were performed using $\chi^{2}$ tests and ANOVA.

\section{RESULTS}

\section{Physical activity}

In $26 \%$ of all consultations, the general practitioner gave an advice concerning physical activity (564 consultations). This type of advice occurred most frequently in patients with musculoskeletal problems (Fig. 1).

As could have been expected, the top 15 complaints in which PA advice is given mainly involve musculoskeletal complaints and illnesses. However, PA advice was also given in cases of high blood pressure, cough, stomach ache and dizziness (Table 1).

PA advice was more often given in cases where the general practitioner was unable to give a clear cut diagnosis (Table 2).

\section{[ FIGURE 1]}

\section{[TABLE 1]}

\section{[TABLE 2]}

Patient and general practitioner characteristics Tables 3 and 4 give an overview of the differences in likelihood of a PA advice between patients and between general practitioners. For these analyses only consultations were selected which involved diagnoses or complaints in which theoretically a PA advice could have occurred.

Given this selection, PA advice was given significantly more often in consultations with male patients and patients aged between 16 and 40. There are no significant differences in the likelihood of a PA advice according to level of education and type of health insurance.

General practitioners who work less than half time and general practitioners with practices in more urban areas, more often give a PA advice. Characteristics of the general practitioner 
Maas, J. Are health benefits of physical activity in natural environments used in primary care by general practitioners in The Netherlands? Urban Forestry \& Urban Greening: 2007, 6(4), 227-233

like gender, age and type of practice were not related to the probability of giving a PA advice.

\section{[TABLE 3]}

Nature A random sample of 100 videotaped consultations with a PA advice was drawn in order to investigate whether nature, green space or equivalent was mentioned.

Nature was mentioned in only two of these. In one consultation a patient suffering from chest pain and dizziness said he walked for half an hour daily, preferably in a urban environment, because "if something happens, there is always someone near to help me". In the other consultation a patient was advised not to "remain sitting behind the geraniums". To sit behind the geraniums is a Dutch expression for inactivity. In sum, nature was not mentioned during any of the videotaped consultations.

\section{DISCUSSION}

Literature suggests that people's health benefits from both physical activity and the presence of nature.

\section{[TABLE 4]}

Additionally, there are indications that the combination of the two, physical activity in a natural environment, has synergic health effects as opposed to physical activity in other settings. More specifically, literature shows that being physically active, nature and being physically active in nature can prevent for example overweight, diabetes and stress. To a limited extent these insights are used in health care. For example, there is an increasing number of agricultural farms that are used as a basis for promoting mental and physical health and well-being (Hassink and van Dijk, 2006). Also hospitals and nursing homes are increasingly aware of the benefits of green space and nature areas (healing gardens) (van den Berg, 2005).

And finally, in primary care the health benefits of physical activity, nature and physical activity in nature are used in a some countries. In New Zealand people get a written physical activity advice from their general practitioner (Elley et al., 2003). In the UK there are initiatives for promoting physical activity in natural environments Green Gym (2007).

However, it was unknown whether the health benefits of physical activity in a natural environment are used in patient consultations by Dutch general practitioners in primary care. This study shows that Dutch general practitioners regularly advice patients to be physically active, especially in patients who suffer from musculoskeletal problems, and problems concerning the nervous system. However, they do not mention the possible additional benefits of physical activity in nature areas.

There may be several reasons for the fact that only general practitioners in the UK advice patients to be physically active in a natural environment. First, general practitioners might not believe in the extra benefit of being physically active in a natural environment.

General practitioners mainly prescribe treatment which is evidence based, which is legitimate in the field of research and which pays back in terms of economic structure. Knowledge on the relation between nature and health is low ranked in the medical fields.

Second, they do not have time to discuss this with patients. Another reason for the differences found between the UK and The Netherlands probably lies in the design of the study. Watching a random selection of consultation of general practitioners may yield similar results in the UK, as initiatives for promoting physical activity in a natural environment are a rather new phenomena, even in the UK.

For The Netherlands as well as for other countries, we believe that in the short run the use of the positive relation between nature and health can perhaps be improved by providing and distributing information in general practice about the health benefits of physical activity in 
Maas, J. Are health benefits of physical activity in natural environments used in primary care by general practitioners in The Netherlands? Urban Forestry \& Urban Greening: 2007, 6(4), 227-233

natural areas, and about the possibilities that local facilities can offer in this respect. However, given the fact that medical treatment is increasingly evidence based, we think that the scientific evidence for the health benefits of physical activity in nature needs to be stronger. More knowledge is needed about the precise type of nature patients need to get the highest health benefits. Will a walk down a tree lined street suffice? Or does nature need to be more like a park or forested area? Results from such research could eventually find their way into the guidelines for general practitioners that are issued by professional general practitioners organizations in many countries. Only then there is a possibility that nature will start to play a role in primary care.

\section{ACKNOWLEDGEMENT}

This research was funded by The Dutch State Forestry Service.

\section{REFERENCES}

van den Berg, A.E., 2005. Health impacts of healing environments: a review of evidence for benefits of nature, daylight, fresh air, and quiet in healthcare settings.

Groningen.

van den Berg, A.E., Koole, S.L., van der Wulp, N.Y., 2003.

Environmental preference and restoration: (How) are they related? Journal of Environmental Psychology 23, 135-146.

Bodin, M., Hartig, T., 2003. Does the outdoor environment matter for psychological restoration gained through running? Psychology of Sport and Exercise 4, 141-153.

Booth, M.L., Owen, N., Nauman, A., Clavisi, O., Leslie, E., 2000. Social-cognitive and perceived environment influences associated with physical activity in older Australians. Preventive Medicine 31, 15-22.

van den Brink-Muinen, A., van Dulmen, A., Schellevis, F.G., Bensing, J.M., 2004. Oog voor communicatie: huisartspatient communicatie in Nederland (eye for communication: GPpatie" nt communication in The Netherlands).

NIVEL, Utrecht (in Dutch).

den Dulk, C.J., Stadt, H., Vliegen, J.M., 1999. Een nieuwe maatstaf voor stedelijkheid: de omgevingsadressendichtheid (a new measurement for urbanity: the environmental address density). Maandstatistiek van de bevolking 7, 14-22 (in Dutch).

Ellaway, A., Macintyre, S., Bonnefoy, X., 2005. Graffiti, greenery, and obesity in adults: secondary analysis of European cross sectional survey. British Medical Journal 331, 611612.

Elley, C.R., Kerse, N., Arroll, B., Robinson, E., 2003.

Effectiveness of counseling patients on physical activity in general practice: cluster randomized controlled trial. British Medical Journal 326, 793-798.

Green Gym, 2007. Website, /http://www.greengym.org.uk/S (accessed March 2007).

Hartig, T., Mang, M., Evans, G.W., 1991. Restorative effects of natural environment experiences. Environment and Behavior 23, 3-27.

Hassink, J., van Dijk, M., 2006. Farming for Health. Springer, Wageningen.

Health Council of the Netherlands and Nature and the environment Dutch Advisory Council for research on Spatial Planning, 2004. Nature and Health. The Influence of Nature on Social, Psychological and Physical Wellbeing.

Health Council of the Netherlands, RMNO, The Hague.

Hull, R.B.I.V., 1992. Brief encounters with urban forests produce moods that matter. Journal of Arboriculture 18, 322-324.

Kaplan, R., Kaplan, S., 1989. The Experience of Nature. A Psychological Approach. Cambridge University Press, Cambridge.

Lamberts, H., Wood, M., 1987. ICPC. International Classification of Primary Care. Oxford University Press, Oxford etc.

Maas, J., Verheij, R.A., Groenewegen, P.P., de Vries, S., Spreeuwenberg, P., 2006. Green space, urbanity and health: how strong is the relationship? Journal of Epidemiology and Community Health 60, 587-592.

Moore, E.O., Arch, A., 1982. A prison environment's effect on health care service demands. Journal of Environmental Systems 11, 17-34. NIH Consensus Development Panel on 
Maas, J. Are health benefits of physical activity in natural environments used in primary care by general practitioners in The Netherlands? Urban Forestry \& Urban Greening: 2007, 6(4), 227-233

Physical Activity and Cardiovascular Health, 1996. Physical activity and cardiovascular health. Journal of the American Medical Association 276, 241-246.

Oguma, Y., Sesso, H.D., Paffenbarger, J.R.S., Lee, I.M., 2002.

Physical activity and all cause mortality in women: a review of evidence. British Journal of Sports Medicine 36, 162-172.

Pate, R., Pratt, M., Blair, S.N., Haskell, W.L., Macere, C.A., Bouchard, C., Buchner, D., Ettinger, W., Heath, G.W., King, A.C., Kriska, A., Leon, A.S., Marcus, B.H., Morris, J., Paffenbarger Jr., R.S., Patrick, K., Pollock, M.L., Rippe, J.M., Sallis, J., Wilmore, J.H., 1995. Physical activity and public health: a recommendation from the Centers for Disease Control and Prevention and the American College of Sports Medicine. Journal of the American Medical Association 273, 402-407.

Pretty, J., Peacock, J., Sellens, M., Griffin, M., 2005. The mental and physical health outcomes of green exercise.

International Journal of Environmental Health Research 15, 319-337.

Ru“ tten, A., 2001. Self reported physical activity, public health and perceived environment: results from a comparative European study. Journal of Epidemiology Community Health 55, 139-146.

Scully, D., Kremer, J., Meade, M.M., Graham, R., Dudgeon, K., 1998. Physical exercise and psychological well being: a critical review. British Journal of Sports and Medicine 32, 111120.

Taylor, A.F., Wiley, A., Kuo, F.E., Sullivan, W.C., 1998.

Growing up in the Inner City: green spaces as places to grow. Environment and Behavior 30, 3-28.

Ulrich, R., 1984. View through a window may influence recovery from surgery. Science 224, 420-421.

US Department of Health and Human Services, 1996. Physical activity and health: A report of the Surgeon General.

US Department of Health and Human Services, Centers for Disease Control and Prevention, National Center for Chronic Disease Prevention and Health Promotion, Atlanta.

de Vries, S., Verheij, R.A., Groenewegen, P.P., Spreeuwenberg, P., 2003. Natural environments-healthy environments? An exploratory analysis of the relationship between greenspace and health. Environment and planning A 35, 1717-1731.

de Vries, S.I., Bakker, I., van Mechelen, W., Hopman-Rock, M., 2007. Determinants of Activity-friendly neighborhoods for children: results from the SPACE Study. American Journal of Health Promotion 21 (14 supplement), 312-316.

Westert, G.P., Schellevis, F.G., de Bakker, D.H., Groenewegen, P.P., Bensing, J.M., van der Zee, J., 2005. Monitoring health inequalities through general practice: the Second Dutch National Survey of General Practice. European Journal of Public Health 15, 59-65.

World Health Organization, 1997. Highlights on health in The Netherlands. WHO Regional Office for Europe, Copenhagen. 
FIGURE AND TABLES

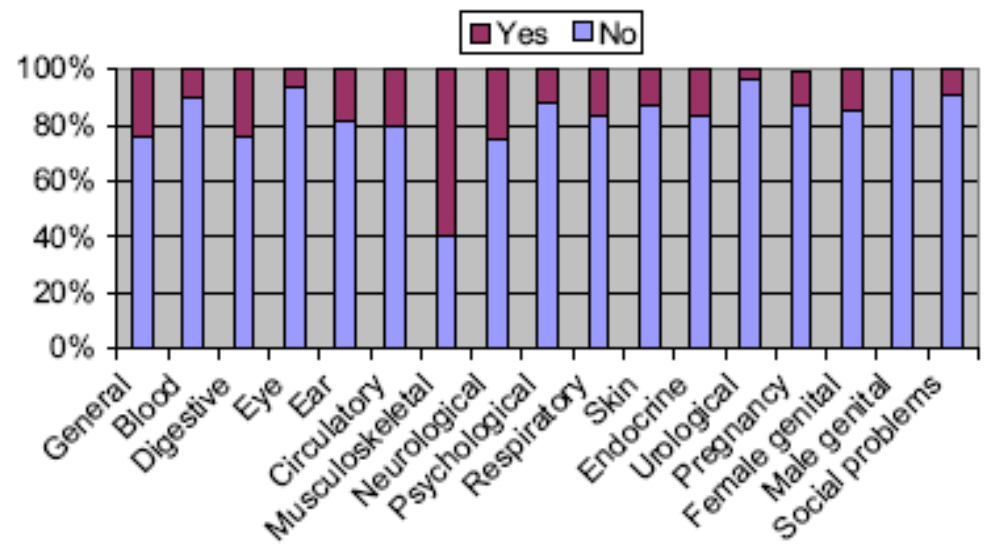

Fig. 1. Percentage of consultations in which physical activity was mentioned per ICPC chapter $(n=2074)$.

Table 1. Top-15 complaints/diagnoses in which a PA advice was given

\begin{tabular}{ll}
\hline Complaint & Percentage of consultations \\
\hline Back complaints & 63 \\
Knee complaints & 40 \\
Shoulder complaints & 23 \\
High blood pressure & 22 \\
Ankle complaints & 22 \\
Neck complaints & 17 \\
Arm complaints & 15 \\
Leg complaints & 15 \\
Feet/toe complaints & 15 \\
Chest complaints & 13 \\
Hand/ finger complaints & 10 \\
Cough & 10 \\
Complaint unknown & 10 \\
Generalised stomach ache & 9 \\
Dizziness & 9 \\
\hline
\end{tabular}

Table 2. Percentage of consultations in which PA advice was given according to diagnosis/symptom recording $(N=2074)$

Physical activity was mentioned (\%)

Consultation in which a diagnosis was 19.5 recorded

Consultations in which a symptom was recorded

$p<.001\left(\chi^{2}\right)$. 
Maas, J. Are health benefits of physical activity in natural environments used in primary care by general practitioners in The Netherlands? Urban Forestry \& Urban Greening: 2007, 6(4), 227-233

Table 3. Percentage of consultations in which PA advice was given, by patient's gender, age, level of education and type of health insurance ${ }^{a}$

\begin{tabular}{lll}
\hline & $\begin{array}{l}\text { Physical activity } \\
\text { mentioned (\%) }\end{array}$ & Significance \\
\hline Gender $(n=829)$ & & $* * *$ \\
$\quad$ Male & 50 & \\
Female & 38.5 & $* *$ \\
Age $(n=829)$ & & \\
$0-15$ & 42.6 & \\
$16-25$ & 54.2 & \\
$26-40$ & 51.6 & \\
$41-55$ & 43.3 & \\
56-65 & 40.9 & \\
$>65$ & 33 & \\
Level of education & & \\
$(n=631)$ & & \\
$\quad$ No education & 45 & \\
Elementary school & 41.7 & \\
Secondary school & 40.1 & \\
Higher education & 53.1 & \\
Type of health insurance & \\
$(n=785)$ & \\
Public insurance & 43 & \\
Private insurance & 44 & \\
\hline
\end{tabular}

${ }^{*} p<0.05 ;{ }^{*} p<.01 ; * * * p<.001 ;$ ns: not significant $\left(\chi^{2}\right)$.

"Only consultations in which the following complaints were mentioned were included in the analysis: fatigue, high blood pressure, overweight, diabetes, complaints conceming musculoskeletal apparatus and mental complaints. 
Maas, J. Are health benefits of physical activity in natural environments used in primary care by general practitioners in The Netherlands? Urban Forestry \& Urban Greening: 2007, 6(4), 227-233

Table 4. Percentage of consultations in which PA advice was given, by general practitioners gender, age, type of practice, number of FTEs and urbanisation level $(n=140)^{\mathrm{a}}$

\begin{tabular}{lll}
\hline & $\begin{array}{l}\text { Physical activity } \\
\text { mentioned (\%) }\end{array}$ & Significance \\
\hline Gender & & ns \\
Male & 44.4 & \\
Female & 43.9 & ns \\
Age & & \\
30-39 & 48.7 & \\
$40-49$ & 48.7 & \\
$50-59$ & 38.2 & \\
60-69 & 40 & \\
Type of practice & & \\
Solo practice & 46 & $* *$ \\
Dual practice & 43.2 & \\
Group practice & 43.6 & \\
Number of whole time & & \\
equivalents (fte) & & \\
t/m 0.5 fte & 67.1 & \\
$0.6-0.7$ fte & 38.5 & \\
$0.8-0.9$ fte & 43.2 & \\
1.0 fte & 42.9 & \\
Urbanisation & & \\
Very highly urban & 44 & \\
Highly urban & 45 & \\
Moderately urban & 42.6 & \\
Slightly urban & 38 & \\
Non urban & 40.8 & \\
\hline
\end{tabular}

${ }^{*} p<0.05 ;{ }^{* *} p<.01 ; * * *<<.001 ;$ ns: not significant (ANOVA).

${ }^{a}$ Only consultations in which the following complaints were mentioned were included in the analysis: fatigue, high blood pressure, overweight, diabetes, complaints concerning the musculoskeletal apparatus and mental complaints. 